\title{
Erratum to: Water intake: validity of population assessment and recommendations
}

\author{
Joan Gandy ${ }^{1}$
}

Published online: 23 July 2015

(C) Springer-Verlag Berlin Heidelberg 2015

\section{Erratum to: Eur J Nutr (2015) 54 Suppl (2):S11-S16 \\ DOI 10.1007/s00394-015-0944-8}

Unfortunately, the Table 1 has been incorrectly published in the original publication. The correct table is given below:

Table 1 Recommended adequate intakes for total water (European Food Safety Authority and Institute of Medicine)

\begin{tabular}{|c|c|c|c|c|}
\hline \multirow[b]{3}{*}{ Age } & \multicolumn{4}{|c|}{ Adequate intake (L/day) } \\
\hline & \multicolumn{2}{|l|}{ EFSA [7] } & \multicolumn{2}{|l|}{ IOM [10] } \\
\hline & Total water intake & Fluid intake ${ }^{a}$ & Total water intake & Fluid intake ${ }^{\mathrm{a}}$ \\
\hline $0-6$ months & $0.68^{\mathrm{b}}$ & $0.68^{\mathrm{b}}$ & 0.70 & 0.70 \\
\hline 6-12 months (IOM 7-12 months) & $0.80-1.00$ & $0.64-0.80$ & 0.80 & 0.60 \\
\hline $1-2$ years & $1.10-1.20$ & $0.88-0.90$ & & \\
\hline $2-3$ years & 1.30 & 1.04 & & \\
\hline $1-3$ years & & & 1.30 & 0.90 \\
\hline $4-8$ years & 1.60 & 1.28 & 1.70 & 1.20 \\
\hline \multicolumn{5}{|l|}{ 9-13 years } \\
\hline Boys & 2.10 & 1.68 & 2.40 & 1.80 \\
\hline Girls & 1.90 & 1.50 & 2.10 & 1.60 \\
\hline \multicolumn{5}{|l|}{$>14$ years as adults } \\
\hline Boys & 2.50 & 2.00 & 3.30 & 2.60 \\
\hline Girls & 2.00 & 1.60 & 2.30 & 1.80 \\
\hline \multicolumn{5}{|l|}{ Adults } \\
\hline Men & 2.50 & 2.00 & 3.70 & 2.60 \\
\hline Women & 2.00 & 1.60 & 2.70 & 1.80 \\
\hline Pregnant women & +0.30 & & +0.30 & 0.10 \\
\hline Lactation women & +0.60 to 0.70 & & +1.10 & 0.90 \\
\hline Elderly & As adults & As adults & As adults & As adults \\
\hline
\end{tabular}

a $80 \%$ of total water intake; ${ }^{b}$ through milk

The online version of the original article can be found under doi:10.1007/s00394-015-0944-8.

Joan Gandy

joan.gandy@btinternet.com

1 School of Life and Medical Services, University

of Hertfordshire, Hatfield AL10 9AB, UK 